\title{
Front Matter: Volume 10399
}

, "Front Matter: Volume 10399," Proc. SPIE 10399, Optics for EUV, X-Ray, and Gamma-Ray Astronomy VIII, 1039901 (5 October 2017); doi:

10.1117/12.2297597

SPIE Event: SPIE Optical Engineering + Applications, 2017, San Diego, California, SPIE. United States 


\section{PROCEEDINGS OF SPIE}

\section{Optics for EUV, X-Ray, and Gamma-Ray Astronomy VIII}

Stephen L. O'Dell

Giovanni Pareschi

Editors

8-10 August 2017

San Diego, California, United States

Sponsored and Published by

SPIE 
The papers in this volume were part of the technical conference cited on the cover and title page. Papers were selected and subject to review by the editors and conference program committee. Some conference presentations may not be available for publication. Additional papers and presentation recordings may be available online in the SPIE Digital Library at SPIEDigitalLibrary.org.

The papers reflect the work and thoughts of the authors and are published herein as submitted. The publisher is not responsible for the validity of the information or for any outcomes resulting from reliance thereon.

Please use the following format to cite material from these proceedings:

Author(s), "Title of Paper," in Optics for EUV, X-Ray, and Gamma-Ray Astronomy VIII, edited by Stephen L. O'Dell, Giovanni Pareschi, Proceedings of SPIE Vol. 10399 (SPIE, Bellingham, WA, 2017) Seven-digit Article CID Number.

ISSN: 0277-786X

ISSN: 1996-756X (electronic)

ISBN: 9781510612556

ISBN: 9781510612563 (electronic)

Published by

SPIE

P.O. Box 10, Bellingham, Washington 98227-0010 USA

Telephone +1 3606763290 (Pacific Time) · Fax +1 3606471445

SPIE.org

Copyright @ 2017 , Society of Photo-Optical Instrumentation Engineers.

Copying of material in this book for internal or personal use, or for the internal or personal use of specific clients, beyond the fair use provisions granted by the U.S. Copyright Law is authorized by SPIE subject to payment of copying fees. The Transactional Reporting Service base fee for this volume is $\$ 18.00$ per article (or portion thereof), which should be paid directly to the Copyright Clearance Center (CCC), 222 Rosewood Drive, Danvers, MA 01923. Payment may also be made electronically through CCC Online at copyright.com. Other copying for republication, resale, advertising or promotion, or any form of systematic or multiple reproduction of any material in this book is prohibited except with permission in writing from the publisher. The CCC fee code is $0277-$ $786 \times / 17 / \$ 18.00$.

Printed in the United States of America.

Publication of record for individual papers is online in the SPIE Digital Library.

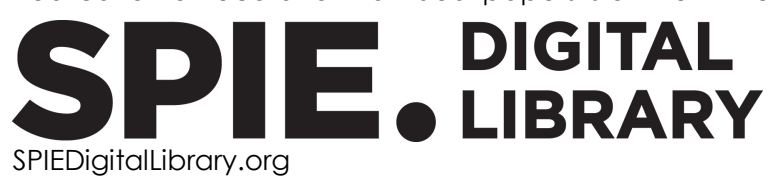

Paper Numbering: Proceedings of SPIE follow an e-First publication model. A unique citation identifier (CID) number is assigned to each article at the time of publication. Utilization of CIDs allows articles to be fully citable as soon as they are published online, and connects the same identifier to all online and print versions of the publication. SPIE uses a seven-digit CID article numbering system structured as follows:

- The first five digits correspond to the SPIE volume number.

- The last two digits indicate publication order within the volume using a Base 36 numbering system employing both numerals and letters. These two-number sets start with 00, 01, 02, 03, 04, 05, 06, 07, 08, 09, OA, OB ... 0Z, followed by 10-1Z, 20-2Z, etc. The CID Number appears on each page of the manuscript. 


\title{
Contents
}

\author{
vii Authors \\ xi Conference Committee \\ xiii Introduction
}

\section{SESSION 1 CHERENKOV TELESCOPES}

1039902 Cherenkov Telescope Array: the next generation gamma ray observatory [10399-1]

1039904 The ASTRI SST-2M prototype for the Cherenkov Telescope Array: status after the commissioning phase of the telescope [10399-3]

1039906 First light on a new fully digital camera based on SiPM for CTA SST-1M telescope [10399-5]

\section{SESSION $2 \quad$ X-RAY TELESCOPES}

1039908 The STAR-X X-Ray Telescope Assembly (XTA) [10399-7]

\section{SESSION 3 ATHENA TELESCOPE}

10399 OB The ATHENA telescope and optics status [10399-10]

10399 OC Development of ATHENA mirror modules [10399-11]

10399 OE Optical integration of SPO mirror modules in the ATHENA telescope [10399-13]

10399 OF Integration of the ATHENA mirror modules: development of indirect and x-ray direct AIT methods [10399-14]

\section{SESSION 4 DESIGN AND ANALYSES}

10399 Ol Optical design of the STAR-X telescope [10399-17]

$10399 \mathrm{OJ}$ Methods for reducing singly reflected rays on the Wolter-I focusing mirrors of the FOXSI rocket experiment [10399-18]

10399 OK Design and simulations of a short optical baffle for the Lightweight Asymmetry and Magnetism Probe (LAMP) [10399-19]

$10399 \mathrm{OL}$ Optical design and simulations of the soft $\mathrm{x}$-ray telescope for Einstein Probe mission [10399-20] 
10399 ON Measuring silicon pore optics [10399-22]

$10399 \mathrm{OQ}$ Reflectivity around the gold L-edges of $\mathrm{x}$-ray reflector of the soft $\mathrm{x}$-ray telescope onboard ASTRO-H [10399-25]

10399 OR The Hitomi (ASTRO-H) Hard x-ray Telescope (HXT): current status of calibration [10399-26]

SESSION 6 MONOCRYSTALLINE-SILICON OPTICS

10399 OS Monocrystalline silicon and the meta-shell approach to building x-ray astronomical optics [10399-27]

10399 OT Progress on the fabrication of lightweight single crystal silicon x-ray mirrors [10399-28]

10399 OU Kinematic alignment and bonding of silicon mirrors for high-resolution astronomical x-ray optics [10399-29]

\section{SESSION 7 FUSED-SILICA OPTICS}

10399 OX Fused silica segments: a possible solution for $\mathbf{x}$-ray telescopes with very high angular resolution like Lynx/XRS [10399-32]

\section{SESSION 8 SLUMPED OPTICS}

$10399 \mathrm{OZ}$ Indirect glass slumping of grazing incidence mirror segments for lightweight x-ray telescopes [10399-34]

1039910 Recent progress on air-bearing slumping of segmented thin-shell mirrors for x-ray telescopes: experiments and numerical analysis [10399-35]

$1039911 \quad$ X-ray mirror prototype based on cold shaping of thin glass foils [10399-36]

1039912 Lamination of ultra-thin silicon wafers for producing high-quality and low-cost x-ray telescope mirrors [10399-37]

\section{SESSION 9 SPECTROMETER AND POLARIMETER OPTICAL COMPONENTS}

1039914 Critical-angle transmission grating technology development for high resolving power soft $x$-ray spectrometers on Arcus and Lynx [10399-39]

1039915 Scanning laser reflection tool for alignment and period measurement of critical-angle transmission gratings [10399-40]

$1039916 \quad$ Laboratory progress in soft x-ray polarimetry [10399-41] 
1039917 REDSoX: Monte-Carlo ray-tracing for a soft x-ray spectroscopy polarimeter [10399-42]

SESSION 10 MULTILAYER COATINGS

1039918 Design, development, and performance of $x$-ray mirror coatings for the ATHENA mission [10399-43]

10399 1A Simulation and optimization of a soft gamma-ray concentrator using thin film multilayer structures [10399-46]

\section{SESSION 11 COATING STRESS}

10399 1B Stress compensating multilayers [10399-47]

10399 1C Development of iridium coated x-ray mirrors for astronomical applications [10399-48]

10399 ID Using ion implantation for figure correction in glass and silicon mirror substrates for x-ray telescopes [10399-49]

\section{SESSION 12 EROSION/DEPOSITION FIGURING}

10399 IF Improving $x$-ray optics via differential deposition [10399-51]

10399 1G Additive manufactured x-ray optics for astronomy [10399-52]

10399 1H Design and modeling of an additive manufactured thin shell for $x$-ray astronomy [10399-53]

SESSION 13 ADJUSTABLE OPTICS

1039911 ThermoYield actuators: nano-adjustable set-and-forget optics mounts [10399-54]

10399 1K Design and fabrication of adjustable $\mathrm{x}$-ray optics using piezoelectric thin films [10399-56]

10399 1M Deterministic figure correction of piezoelectrically adjustable slumped glass optics [10399-58]

10399 iN Controlling the shapes of coated silicon substrates via magnetic fields, a progress report [10399-59]

\section{SESSION 14 OTHER IMAGING TECHNOLOGIES}

10399 1Q Testing and modelling of the SVOM MXT narrow field lobster eye telescope [10399-61]

10399 IR An angular-resolution booster on the broadband $x$-ray telescope system [10399-62] 
10399 is Development of multilayer coatings for hard x-ray optics at NASA Marshall Space Flight Center [10399-44]

10399 IT Readout electronics testing during mass production of FlashCam cameras for the Cherenkov Telescope Array [10399-63]

10399 IW Industrialization of the mirror plate coatings for the ATHENA mission [10399-66]

10399 IX Characterization of multilayer coated replicated Wolter optics for imaging $\mathrm{x}$-ray emission from pulsed power [10399-67] 
Funk, S., $1 T$

Furuzawa, Akihiro, OR

Gadola, A., IT

Gaines, Derek, 16

Gallieni, D., OE

Gargano, Carmelo, 04

Garrecht, F., IT

Gaskin, Jessica A., 14

Gellert, Nis C., 18

Ghigo, Mauro, 0X, 11

Giro, Enrico, 04

Girou, David, OC, ON

Glesener, Lindsay, 0J

Göłz, Diego, 1Q

Gregory, Don, 1S

Grudzińska, Mira, 06

Gullikson, Eric M., 16

Günther, Hans M., 17

Günther, Ramses, OC, ON

Gurgew, Danielle N., 1B, 15

Haba, Yoshito, OR

Haneveld, Jeroen, OB, OC

Harpt, Benjamin E., 1N

Hartner, Gisela D., 11, 14

Hayashi, Takayuki, OQ, OR, IR

Heilmann, Ralf K., 10, 14, 15, 16, 17, 1D, 11

Heine, Sarah N. T., 16, 17

Heller, Matthieu, 06

Hellickson, Tim, 17

Hermann, G., $1 T$

Hertz, Edward, 14, 15, 1K, $1 \mathrm{M}$

Hinze, F., IW

Hlinka, Michal, OS, OT, OU

Hołyszko, Joanna, OX, 11

Houghton, Paul, 1Q

Huang, Qiushi, OL

Hugot, Emmanuel, $1 \mathrm{G}$

lizuka, Ryo, OQ, OR, IR

Ishibashi, Kazunori, OR

Ishida, Manabu, OQ, OR, IR

Ishikawa, Shin-nosuke, OJ

Jackson, Thomas N., 1K, 1M

Jamrozy, Marek, 06

Jung, I., $1 \mathrm{~T}$

Kalekin, O., IT

Kalkuhl, C., IT

Kamenidis, Ifikratis, 18

Kasperek, Jerzy, 06, $1 \mathrm{~T}$

Kearney, John D., OS, OT, OU

Kinm, T., IT

Kikuchi, Naomichi, $0 Q$

Kilaru, Kiranmayee, 1F, 1X

Koelewijn, Arenda, OC

Kolodziejczak, Jeffery, 14, 1F

Korman, Jakob, 18

Kozioziemski, B., 1X

Krucker, Säm, OJ

Krumrey, Michael, OB, OC, OF, ON, 18

Krzanowski, James E., IA

Kunieda, Hideyo, OR
Kurashima, Sho, $0 Q$

La Caria, Marlis-Madeleine, 14

Lahmann, R., IT

Landgraf, Boris, $\mathrm{OB}, \mathrm{OC}, \mathrm{ON}, 18,1 \mathrm{~W}$

Le Duigou, Jean-Michel, $1 Q$

Legere, Jason S., $1 \mathrm{~A}$

Levey, Skylar, 16

Li, Wenbi, OK

Liao, Yingyu, OL

Lièvre, Nicolas, OF

Liu, Tianning, 1K, $1 \mathrm{M}$

Lyard, Etienne, 06

Mach, Emil, 06

Madarasz, Emanuel, $\mathrm{OZ}$

Maeda, Yoshitomo, OQ, OR, IR

Mandat, Dusan, 06

Marchiori, G., 04

Marcuzzi, E., 04

Marioni, F., OE

Marquez, Vanessa, 1M

Marshall, Herman L., 16, 17

Marszalek, A., IT

Martindale, Adrian, 1Q

Massahi, Sonny, OB, OC, 18, IW

Matsumoto, Hironori, $0 Q, O R$

Mazzarella, James R., OS, OU

McClelland, Ryan S., 08, OI, OS, OU

McConnell, Mark L., $1 \mathrm{~A}$

Mercado, Alejandro M., $1 \mathrm{~N}$

Mercier, Karine, 1Q

Michałowski, Jerzy, 06

Mitsuishi, Ikuyuki, OQ, OR

Miyazawa, Takuya, OR

Moderski, Rafal, 06

Montaruli, Teresa, 06

Mori, Hideyuki, OQ, OR

Müller, Peter, OC, OF, ON

Musset, Sophie, OJ

Nakamura, Ryoko, $1 \mathrm{R}$

Narukage, Noriyuki, OJ

Nazeeruddin, Adeeb, OF

Neronov, Andrii, 06

Niemiec, Jacek, 06

Nitta, Kiyofumi, $0 Q$

Njoh Ekoume, T. R. S., 06

Numata, Ai, OS, OU

O'Brien, Paul, 1Q

O'Dell, Stephen L., 14, 1B

O'Donnell, Allison E., IN

Okajima, Takashi, OQ, OR

Oliver, Paul, OB, OC

Olsen, Lawrence G., OS

Osborne, Julian, 1Q

Ostrowski, Michal, 06

Ottolini, M., OE

Pareschi, Giovanni, 04, OB, OC, OE, OX, 11

Parodi, G., OE

Paśko, Paweł, 06

Pearson, James, $1 Q$

Pech, Miroslav, 06 
Pelliciari, Carlo, 11

Petit, Sylvain, 1Q

Pfeifer, M., IT

Pivovaroff, M., $1 \mathrm{X}$

Principe, G., $1 T$

Probst, Anne-Catherine, 0Z, $1 \mathrm{C}$

Proserpio, Laura, $\mathrm{OZ}$

Pühlhofer, G., $1 T$

Pürckhaver, S., $1 T$

Qian, Jun, $1 \mathrm{~N}$

Rafalski, Jakub, 06

Rajda, Paweł, 06, IT

Ramsey, Brian D., 0J, 1B, 1S, 1X

Rasmussen, Ida F., 18

Reid, Paul B., 1K, $1 \mathrm{M}$

Reimer, O., $1 \mathrm{~T}$

Riveros, Raul E., OS, OT, OU

Romaine, S., IX

Roudot, Romain, 1Q

Roulet, Melanie, 1G, 1H

Russo, Federico, 04

Saha, Timo T., Ol, OS, OU

Sailer, S., IT

Saji, Shigetaka, $0 Q$

Salmaso, Bianca, 0X, 11

Santangelo, A., $1 T$

Sato, Toshiki, OQ, IR

Schaeffer, Uwe, OF

Schanz, T., IT

Schattenburg, Mark L., 10, 12, 14, 15, 1D, 11

Schovanek, Petr, 06

Schreiber, Swenja, 0N, 18

Schulz, Norbert S., 16, 17

Schwab, T., $1 T$

Schwartz, Eric D., 1K, 1M

Schyns, Emile, 1Q

Scuderi, Salvatore, 04

Seidel, André, OB

Seure, Thibault, OF

Seweryn, Karol, 06

Sforzini, Jessica, OC, IW

Sharpe, Marton V., OU

Shen, Zhengxiang, OL

Shirazi, Farzane, lA

Shortt, Brian, OB, OC, 18, IW

Sironi, Giorgia, 04

Skowron, Krzysztof, 06

Sliusar, Vitalii, 06

Smith, Randall K, 14

Solly, Peter M., OS

Song, Jungki, 14, 15

Spiga, Daniele, OB, OE, OX

Stawarz, Łukasz, 06

Stehlíková, Veronika, 0Z, 1C

Steiner, S., $1 T$

Stodulska, Magdalena, 06

Stodulski, Marek, 06

Stollenwerk, Manfred, 1C

Straumann, U., IT

Sugita, Satoshi, OR
Sykes, John, 1Q

Tachibana, Sasagu, $0 Q$

Tamura, Keisuke, OR

Tawara, Yuzuru, OR

Tedesco, Ross E., 11

Tendulkar, Mohit, 1K, 1M

Tenzer, C., IT

Theriault-Shay, Adam, 17

Tosti, Gino, 04

Travnicek, Petr, 06

Trolier-McKinstry, Susan, 1K, 1M

Troyano Pujadas, Isaac, 06

Turin, Paul, OJ

Ulmer, Melville P., 1N

Uruga, Tomoya, $0 Q$

Vacanti, Giuseppe, OB, OC, ON

Valsecchi, Giuseppe, OB, OC, OE

van Baren, Coen, OB, OC

van der Hoeven, Roy, OC, ON

Vecchi, Gabriele, OX, 11

Vernani, Dervis, OB, OF

Vervest, Mark, OC, ON

Vievering, Juliana, OJ

Vikhlinin, Alexey A., 1M

Vogel, J. K., IX

Vollhardt, A., IT

Walker, Julian, 1K, 1M

Walter, Roland, 06

Walton, C., $1 \mathrm{X}$

Wang, Xiaoli, $1 \mathrm{~N}$

Wang, Zhanshan, OK, OL

Watson, Stephen, 1G, 1H

Werner, F., IT

Wijnperle, Maurice, $O C$

Wille, Eric, $O B, O C, O E, O F, O N$

Willingale, Richard, 1G, 1H, 1Q

Windt, David L., 16

Wolf, D., IT

Wu, M., $1 X$

Xing, Yujie, OK

Yamauchi, Shigeo, OR

Yao, Youwei, 10, 12, 1D

Yoshida, Tessei, OR

Yu, Jun, OK

Zagdański, Adam, 06

Zhang, William W., OI, OS, OT, OU

Ziętara, Krzysztof, 06, $1 T$

Zocchi, F. E., OE

Zuknik, Karl-Heintz, OB, OC

Zuo, Heng E., 10, 1D 
Proc. of SPIE Vol. 10399 1039901-10 Downloaded From: https://www.spiedigitallibrary.org/conference-proceedings-of-spie on 26 Apr 2023
Terms of Use: https://www.spiedigitallibrary.org/terms-of-use 


\section{Conference Committee}

Program Track Chair

Oswald H. Siegmund, University of California, Berkeley (United States)

Conference Chairs

Stephen L. O'Dell, NASA Marshall Space Flight Center (United States) Giovanni Pareschi, INAF - Osservatorio Astronomico di Brera (Italy)

Conference Program Committee

Hisamitsu Awaki, Ehime University (Japan)

Nicolas M. Barrière, cosine Science \& Computing B.V. (Netherlands)

Marcos Bavdaz, European Space Research and Technology Center (Netherlands)

Vadim Burwitz, Max-Planck-Institut für extraterrestrische Physik

(Germany)

Finn E. Christensen, DTU Space (Denmark)

Peter Friedrich, Max-Planck-Institut für extraterrestrische Physik (Germany)

Filippo Frontera, Universitá degli Studi di Ferrara (Italy)

Tim Greenshaw, University of Liverpool (United Kingdom)

Fiona A. Harrison, California Institute of Technology (United States)

René Hudec, Astronomical Institute of the ASCR, v.v.i. (Czech Republic)

Hideyo Kunieda, Nagoya University (Japan)

Randall L. McEntaffer, Pennsylvania State University (United States)

Noriyuki Narukage, National Astronomical Observatory of Japan (Japan)

Mikhail N. Pavlinsky, Space Research Institute (Russian Federation)

Robert Petre, NASA Goddard Space Flight Center (United States)

Brian D. Ramsey, NASA Marshall Space Flight Center (United States)

Paul B. Reid, Harvard-Smithsonian Center for Astrophysics (United States)

Suzanne E. Romaine, Harvard-Smithsonian Center for Astrophysics (United States)

Mark L. Schattenburg, Massachusetts Institute of Technology (United States)

Daniele Spiga, INAF - Osservatorio Astronomico di Brera (Italy)

Yuzuru Tawara, Nagoya University (Japan)

Richard Willingale, University of Leicester (United Kingdom)

David L. Windt, Reflective X-Ray Optics LLC (United States) 
William W. Zhang, NASA Goddard Space Flight Center (United States)

\section{Session Chairs}

1 Cherenkov Telescopes

Tim Greenshaw, University of Liverpool (United Kingdom)

2 X-Ray Telescopes

Hisamitsu Awaki, Ehime University (Japan)

3 ATHENA Telescope

Marcos Bavdaz, European Space Research and Technology Center (Netherlands)

4 Design and Analyses

Randall L. McEntaffer, The University of lowa (United States)

5 Metrology and Testing

Vadim Burwitz, Max-Planck-Institut für extraterrestrische Physik (Germany)

6 Monocrystalline-Silicon Optics

Michael J. Pivovaroff, Lawrence Livermore National Laboratory (United States)

7 Fused-Silica Optics

Kai-Wing Chan, NASA Goddard Space Flight Center (United States) and University of Maryland Baltimore, County (United States)

8 Slumped Optics

William W. Zhang, NASA Goddard Space Flight Center (United States)

9 Spectrometer and Polarimeter Optical Components

Nicolas M. Barrière, cosine \& Computing B.V. (Netherlands)

10 Multilayer Coatings

Qiushi Huang, Tongji University (China)

11 Coating Stress

Desiree Della Monica Ferreira, DTU Space (Denmark)

12 Erosion/Deposition Figuring

Mark Schattenburg, MIT Kavli Institute for Astrophysics and Space Research (United States)

13 Adjustable Optics

Daniele Spiga, INAF - Osservatorio Astronomico di Brera (Italy) 
14 Other Imaging Technologies

Brian Ramsey, NASA Marshall Space Flight Center (United States)

Proc. of SPIE Vol. 10399 1039901-13

Downloaded From: https://www.spiedigitallibrary.org/conference-proceedings-of-spie on 26 Apr 2023 Terms of Use: https://www.spiedigitallibrary.org/terms-of-use 


\section{Introduction}

The conference, Optics for EUV, X-Ray, and Gamma-Ray Astronomy VIII met 810 August, in San Diego, California, as part of the SPIE Optics + Photonics 2017 international symposium, Optical Engineering + Applications. This conference provides a forum for discussion of recent progress in imaging and spectroscopic optics for high-energy astronomy. As with previous biennial conferences in this series, the conference was well-attended by international researchers, including graduate-student and post-doctoral scientists, and featured approximately 65 oral or poster papers.

The success of the conference reflects the vitality of the high-energy astronomy community working in optics and imaging telescopes. The current environment is particularly positive, as facility-class $x$-ray and gamma-ray observatories have recently been approved for implementation or for advanced study. These include the large space-based $x$-ray observatories ATHENA (selected by ESA as the $\mathrm{L} 2$ mission of the Cosmic Visions program) and Lynx (being studied by NASA for consideration during the next US Decadal Survey, as a worthy successor to the Chandra X-ray Observatory), as well as the ground-based Cherenkov Telescope Array (CTA) gamma-ray observatory, being implemented by a large international consortium. In parallel, other smaller x-ray missions (SRG, IXPE, $X A R M$, eXTP, and Einstein Probe) are at various stages of implementation or study.

Session 1 was devoted to ground-based Cherenkov Telescopes for gamma-ray astronomy in the TeV domain. Imaging Atmospheric Cherenkov Telescopes (IACTs) are arrays of moderate-angular-resolution, normal-incidence mirrors that provide stereoscopic imaging of Cherenkov light emitted in upperatmosphere showers, initiated by interaction of cosmic gamma rays with the atmosphere. The presentations addressed technological efforts for realization of low-cost telescopes of different size classes and designs for the upcoming CTA (Cherenkov Telescope Array) project. In this context, an interesting review discussed analogies between dual-mirror telescopes for IACT applications and for grazing-incidence Wolter-like x-ray telescopes. In each case, the configurations have been inspired by the work of Karl Schwarzschild on the design of aplanatic telescopes.

Session 2 concerned design and development of various X-Ray Telescopes, e.g., the Imaging X-ray Polarimetry Explorer (IXPE, recently selected by NASA as a SMEX mission), STAR-X (a wide-field $x$-ray telescope using thin monocrystallinesilicon segmented mirrors), the small-optics systems MiXO (Miniature Lightweight X-ray Optics), and CubeX (Cubesat X-ray telescope) for solar-system exploration. 
Session 3 reported development and implementation of the ATHENA Telescope, which ESA has selected as the second large-class (L2) mission in its Cosmic Vision program. The requirements of $2 \mathrm{~m}^{2}$ effective area and 5" angular resolution are enabled by innovative $x$-ray optics based upon silicon-pore mirror technology. Presented papers reported the status of the ATHENA telescope and optics, as well as detailed descriptions by industrial and scientific partners of aspects related to manufacturing, integration, testing, and calibration.

Session 4 addressed the design and analyses aspects of various $x$-ray missions. These included ATHENA, STAR-X, and the two future Chinese missions (EXTP and Einstein Probe) with international participation.

Session 5 dealt with the metrology and testing of astronomical x-ray optics. Some papers addressed the ATHENA optics, in particular, how to perform a reliable metrology and calibration program for silicon-pore-optics modules. Other papers reported on calibrations of mirror modules for the Hitomi mission.

Sessions 6 and 7 reported methods for direct fabrication of light-weight, highangular-resolution, high-throughput $x$-ray mirrors. For the monocrystalline-silicon optics, the fabrication process slices a thin mirror from a figured block of singlecrystal silicon, which is ideally free of internal stress. For the thin fused-silica optics, the fabrication process directly figures and polishes the thin substrate. These approaches aim to maintain Chandra's sub-arcsecond resolution while providing 10-30 greater throughput. Each shows promising Initial results and anticipates ion-beam figuring to correct residual low-frequency errors.

Session 8 concerned slumped optics. Reports on hot slumping of thin glass substrates, such as used for the NUSTAR hard x-ray mission and considered for the IXO optics, focused primarily on fabrication of substrates for deformable $x$ ray mirrors. In contrast, the session also discussed cold slumping of thin glass substrates for high-throughput x-ray mirrors.

Session 9 described recent developments in spectrometer and polarimeter optical components for x-ray astronomy. The report on critical-angle transmission (CAT) gratings pointed to high-resolution-spectroscopy applications for medium (ARCUS) and for large (Lynx) x-ray astronomy missions. Papers on a proposed soft $\mathrm{x}$-ray spectroscopy polarimeter (REDSOX) described using CAT gratings in combination with laterally graded multilayers working near the Brewster angle.

Session 10 and Session 11 reported, respectively, on recent developments and applications for multilayer coatings and on the related issue of coating stress. While high-reflectance coatings enhance and extend to high energies the effective area, internal stress caused by the coating itself can distort the thin mirrors envisioned for light-weight $x$-ray optics.

Session 12 addressed erosion/deposition figuring techniques aimed at producing precise profiles for thin substrates. These post-fabrication methods include ion figuring, differential deposition (additive machining), and ion implantation to manipulate stress in thin substrates. As a novel extrapolation of additive machining, two papers reported on a UK research effort toward utilizing 3D printing for fabricating $x$-ray optics. 
Session 13 concerned adjustable optics, one of the new frontiers for implementing future $x$-ray telescopes (e.g., Lynx) of large effective area and excellent imaging quality. Papers in this session reported progress in piezoelectric and magnetostrictive actuators

Session 14 reported other imaging technologies for $x$-ray astronomy. These included lobster-eye optics for large-field-of-view monitoring and an interesting approach to boosting imaging resolution of a moderate-resolution focusing telescope using a rotating collimator.

We are grateful to the Program Committee, session chairs, authors, and SPIE staff for their contributions to this successful conference.

Finally, we sadly note the passing of our dear friend and colleague Mikhail (Misha) Gubarev in early 2017. As a talented optical physicist at NASA Marshall Space Flight Center, Misha made numerous contributions to metrology and fabrication of $x$-ray and neutron optics.

Giovanni Pareschi Stephen L. O'Dell 
Proc. of SPIE Vol. 10399 1039901-17 Downloaded From: https://www.spiedigitallibrary.org/conference-proceedings-of-spie on 26 Apr 2023
Terms of Use: https://www.spiedigitallibrary.org/terms-of-use 